\title{
Agricultura familiar, processamento de alimentos e avanços e retrocessos na regulamentação de alimentos tradicionais e artesanais
}

\author{
Family farming, food processing and advances and setbacks in the \\ regulation of traditional and artisanal foods
}

\author{
Fabiana Thomé da Cruz ${ }^{1}$ (D) \\ ${ }^{1}$ Escola de Agronomia (EA), Universidade Federal de Goiás (UFG), Goiânia (GO), Brasil. E-mail: fabianathome@ufg.br
}

\begin{abstract}
Como citar: Cruz, F. T. (2020). Agricultura familiar, processamento de alimentos e avanços e retrocessos na regulamentação de alimentos tradicionais e artesanais. Revista de Economia e Sociologia Rural, 58(2), e190965. https://doi.org/10.1590/1806-9479.2020.190965
\end{abstract}

\begin{abstract}
Resumo: No Brasil, a década de 1990 representa um marco no que se refere a políticas públicas voltadas à agricultura familiar. Dentre essas políticas, merecem atenção as de estímulo à agroindustrialização de alimentos, que incentivaram inúmeras famílias a processar e a comercializar seus produtos. Como consequência, nas últimas décadas, o número de agroindústrias rurais familiares, sejam formais, sejam informais, cresceu significativamente. Porém, apesar do incentivo à agroindustrialização, esses alimentos são processados e comercializados, em sua maioria, à margem do setor formal, o que ocorre devido, principalmente, aos critérios presentes nos regulamentos sanitários vigentes. Ainda que nos últimos anos tenha havido mudanças favoráveis à legalização de agroindústrias familiares, persistem lacunas e desafios importantes que têm contribuído para a informalidade do setor. Nesse contexto, o objetivo deste artigo é ampliar o debate em torno das características e definições associadas ao processamento de alimentos no âmbito da agricultura familiar e analisar regulamentos federais que constituem o marco regulatório sanitário para esses alimentos no Brasil. Para tanto, além de contextualizar o processamento de alimentos pela agricultura familiar, este artigo analisa regulamentos sanitários que incidiram ou incidem sobre essa atividade agrícola, procurando contemplar distintos valores e qualidades em disputa e também possibilidades para superar lacunas relacionadas a produtos agroalimentares tradicionais e artesanais.
\end{abstract}

Palavras-chave: processamento de alimentos, agroindústrias familiares, produtos agroalimentares tradicionais e artesanais, legislação sanitária.

\begin{abstract}
In Brazil, the 1990s represent a milestone in public policies for family farming. Among these policies, that one's focused on stimulating food agroindustrialization are especially relevant because encouraged numerous rural families to process and commercialize their products. As a consequence, in the last decades, the number of family-farm agroindustries, formal or informal, has grown significantly. However, in spite of the public incentive to agroindustrialization, these foods are mostly processed and commercialized informally due, mainly, to the criteria set by the health regulations. Although in recent years positive changes can be noticed in relation to the legalization of family-farm agroindustries, there are remaining gaps and important challenges that have contributed to the expressive number of food processing in an informal way. In this context, the aim of this paper is to broaden the debate on the characteristics and definitions associated with food processing within the family farm and to analyze some Brazilian health regulations related to these products. Therefore, in addition to this contextualization, this paper analyzes health regulations that affect or influence food process activities, seeking to contemplate not only different values and qualities in dispute but also possibilities to overcome gaps and challenges in relation to the artisanal and traditional agrifood products.
\end{abstract}

Keywords: food processing, family-farm agroindustry, artisanal and traditional agrifood products, health regulation. 


\section{Introdução}

No Brasil, em que pesem a importância de programas governamentais de fomento ao processamento de alimentos em agroindústrias familiares e a expressiva produção acadêmica em torno do tema desde a década de 1990, o processamento de alimentos no meio rural, principalmente no âmbito da agricultura familiar, continua sendo questão de debates no que se refere às características dos produtos provenientes desses espaços produtivos, especialmente no que diz respeito à necessidade de haver um marco regulatório específico para esse tipo de produção.

De acordo com uma sistematização proposta por Gazolla (2013), se, por um lado, muitos foram os avanços em relação à definição e às características do que, a partir da década de 1990, passou a ser chamado de agroindústria familiar rural ${ }^{1}$, em relação ao processamento realizado em âmbito doméstico, não raro, nas cozinhas de casa, é possível inferir que são significativamente menos numerosos os trabalhos e referências disponíveis. Isso se deve, em boa medida, à invisibilidade desse tipo de processamento realizado de modo informal ${ }^{2}$. Essa reflexão possibilita, por um lado, evidenciar a amplitude do setor informal de processamento de alimentos pela agricultura familiar e, por outro lado, demonstra a heterogeneidade presente no contexto do que, simplificando a realidade, chama-se de agroindústrias familiares rurais, ou seja, de modo geral, considera-se agroindústria familiar rural tanto o caso de espaços exclusivos para o processamento de alimentos, sejam associados a agroindústrias legalizadas ou informais, quanto o caso do processamento realizado em espaços "adaptados" da cozinha da casa ou em peça contígua à cozinha. Mas, entre essas situações, há diferenças importantes que, entre outros aspectos, remetem à escala de produção, à mão de obra disponível, à disponibilidade de matéria-prima e à renda oriunda da comercialização desses produtos.

De certo modo, estudos e pesquisas sobre agroindústrias familiares rurais legalizadas ou estruturadas de modo a atender aos requisitos para a legalização são mais recorrentes, porém, quando se trata do processamento informal de alimentos realizado no meio rural, as pesquisas acadêmicas são menos presentes. Apesar das poucas pesquisas sobre o setor, é válido ressaltar que não se trata de uma atividade sem expressividade numérica ou com baixa importância econômica para o contexto brasileiro. Fernandes Filho \& Campos (2003), por exemplo, considerando dados de 1995 e 1996, apontam que, naquele período, havia, no Brasil, 887.411 propriedades familiares que processavam algum tipo de alimento para venda, número associado a $18,3 \%$ do total dos estabelecimentos rurais brasileiros. Além de gerar importante receita para o País, atividades de processamento de alimentos são importantes para as famílias produtoras que recebem, em média, renda equivalente a quatro salários mínimos (Fernandes Filho \& Campos, 2003).

Bigheline da Silveira (2013), com base em dados de pesquisa sobre informalidade na comercialização de alimentos da agricultura familiar na região central do Rio Grande do Sul, argumenta que essa forma de comercialização está fortemente alicerçada no excedente do autoconsumo, como é o caso de produtos como ovos, queijo, mel, banha, feijão, galinha, vinho, mandioca e ovelha. Porém, em relação a alguns produtos, a produção tem como finalidade a comercialização e não o consumo da família. Entre os produtos pesquisados

\footnotetext{
${ }^{1}$ Além de agroindústria familiar rural, outros termos que têm sido adotados para se referir ao processamento de alimentos pela agricultura familiar em agroindústrias são agroindústria familiar, agroindústria caseira, artesanal e/ou colonial e agroindústria rural de pequeno porte. Apesar das diferentes nomenclaturas, considera-se, neste artigo, que se trata de "[...] uma forma de organização em que a família rural produz, processa e/ou transforma parte de sua produção agrícola e/ou pecuária, visando sobretudo à produção de valor de troca que se realiza na comercialização" (Mior, 2005, p. 191).

${ }^{2}$ Neste artigo, será feita referência a agroindústrias familiares formais e informais, optando-se por não mencionar termos como ilegal ou clandestino para se referir ao caso de agroindústrias informais. Tal opção decorre da distinção entre informalidade e clandestinidade, apontada por Wilkinson \& Mior (1999), autores que explicam tal distinção argumentando que "[...] o setor informal distingue-se do ilegal pelo fato de seus produtos não serem proibidos, como no caso de drogas ou contrabando. Trata-se de uma atividade cujos processos de produção não se enquadram nos padrões de regulação vigentes. Enquanto no primeiro caso o órgão repressor apropriado é a polícia, no segundo os organismos de fiscalização são responsáveis pelo enquadramento. O setor informal, portanto, é definido fundamentalmente a partir das normas reguladoras do Estado" (Wilkinson \& Mior, 1999, p. 31).
} 
pelo autor, a maioria possui origem informal. Dos produtos consumidos, o autor explica que $22,4 \%$ eram comprados informalmente e $39,6 \%$ não eram comercializados, mas sim recebidos como doação, não sendo, portanto, sequer considerados informais já que não eram comercializados.

Pellegrini \& Gazolla (2008) consideram a informalidade institucional das agroindústrias o grande problema encontrado para a comercialização dos produtos oriundo desse tipo de empreendimento. Nesse sentido, os autores, ao se referirem à Região do Médio Alto Uruguai, no norte do Rio Grande do Sul, indicam que $72,64 \%$ das iniciativas relacionadas ao processamento de alimentos são informais. Eles consideram que os elevados dados associados à informalidade são decorrência dos requisitos sanitários estabelecidos pelas agências de regulação do estado. Nesse sentido, Deon (2015) argumenta que, em que pesem políticas de fomento às agroindústrias familiares rurais, a intervenção pública não tem garantido o desenvolvimento adequado de tais iniciativas, fato que se expressa no número elevado de agroindústrias à margem do setor formal. $O$ autor ilustra a situação com base em dados do Censo Agropecuário de 2006, que fazem referência a 571.643 estabelecimentos agropecuários com agroindústria rural no Brasil (Instituto Brasileiro de Geografia e Estatística, 2006). Apesar desses dados, como pondera o autor, "[...] as estatísticas oficiais não permitem precisão quanto à parcela dessas agroindústrias que estão na informalidade [...]", existindo estudos pontuais que sugerem "expressiva existência de agroindústrias familiares em situação de informalidade" (Deon, 2015, p. 35).

A ausência de dados mais abrangentes e qualificados que possibilitem compreender a relevância do setor informal de processamento de alimentos em agroindústrias familiares rurais pode ser compreendida também como um indicativo da invisibilidade desse setor. Dentre as consequências de tal invisibilidade, é possível que, ainda que nos últimos anos tenha havido avanços no marco legal para o processamento de alimentos por agricultores familiares, tais avanços parecem insuficientes para garantir ampla inserção de alimentos processados de modo tradicional e/ou artesanal no mercado formal.

Dentre as demandas que vem sendo pautadas em agendas de pesquisa para esse tipo de produção ${ }^{3}$, é recorrente a menção à necessidade de um marco regulatório específico, o que evitaria tensões e risco de apreensões pelos produtores durante a comercialização dos produtos. Essa produção contempla a realidade de numerosas famílias que processam pequenas quantidades de produtos se comparadas, por exemplo, a agroindústrias familiares que estão formalizadas. Trata-se, como argumentou Bigheline da Silveira (2013), de produção que garante a alimentação da família e, por meio da comercialização do excedente, proporciona alguma renda extra. Embora, em sua maioria, sejam comercializados informalmente, são produtos de singularidade, amplamente valorizados e demandados por consumidores (Bigheline da Silveira, 2013; Cruz, 2012; Chalita et al., 2009).

Considerando esse contexto, a presente análise volta-se para problematizar a atividade de processamento de alimentos que, em geral não formalizada, ocorre em muitos estabelecimentos rurais de pequeno porte. Nesse sentido, o objetivo deste artigo é ampliar o debate em torno das características e definições associadas ao processamento de alimentos no âmbito da agricultura familiar e, com foco voltado ao processamento tradicional e/ou artesanal, analisar regulamentos federais que constituem o marco regulatório sanitário para o processamento de alimentos no Brasil.

Para atender a esse objetivo, além de revisão e sistematização de literatura sobre o tema, a metodologia adotada para o desenvolvimento deste artigo fundamenta-se na compilação e análise dos principais regulamentos sanitários publicados no Brasil, tomando como ponto de partida a publicação do RIISPOA, na década de 1950. Os objetivos dos principais regulamentos e o enfoque de cada um deles foram sistematizados e, posteriormente, analisados à luz da realidade da produção tradicional e/ou artesanal de

\footnotetext{
${ }^{3}$ Cabe aqui especial referência aos trabalhos e debates que vêm sendo realizados no âmbito da Rede Sial Brasil que, entre as pautas de sua agenda de pesquisa, contempla a definição de produto agroalimentar artesanal, a qual poderá, futuramente, balizar inclusive políticas públicas e regulamentos para o processamento desses produtos que, em geral, são processados em escala bastante reduzida.
} 
alimentos da agricultura familiar. Longe de esgotar a discussão ou apresentar panorama completo sobre os processos em curso em relação ao tema, os dados oriundos de regulamentos sanitários brasileiros possibilitam analisar como estes incidem no Brasil, buscando identificar fatos e avanços relevantes para a realidade não apenas de agroindústrias familiares, mas principalmente para o contexto do processamento tradicional e/ou artesanal de alimentos.

$\mathrm{O}$ debate proposto se justifica por dois aspectos principais. Um deles diz respeito à valorização crescente de alimentos com vínculos aos locais de produção, seja pelas características edafoclimáticas, seja por características socioculturais que conformam um conjunto de condições e conhecimentos propícios à produção de alimentos de qualidade singular, crescentemente valorizados pelo mercado consumidor. Outro aspecto remete à escassez de trabalhos acadêmicos que analisam o processamento tradicional de alimentos que, com frequência, é realizado de modo informal, não raro nas cozinhas de casa. Sobre esses produtos, que estão, em sua maioria, à margem do setor formal, há poucas pesquisas, principalmente com o enfoque de sistematizar e analisar o aparato regulatório sanitário que incide sobre esses produtos, o que, no limite, poderia proporcionar a qualificação e legalização desse tipo de produção.

Sustentando-se pelo contexto e justificativa aqui apresentados, além desta introdução, o artigo está organizado em duas seções seguidas das considerações finais. A primeira seção, que apresenta a fundamentação teórica sobre a qual o artigo está alicerçado, explora as características e definições associadas ao processamento de alimentos no âmbito da agricultura familiar, buscando distinguir a lógica associada às agroindústrias familiares da que se refere ao processamento que historicamente acontece nos espaços domésticos das famílias rurais, entendido neste artigo como processamento tradicional de alimentos ou de produtos agroalimentares artesanais. Essas definições são possíveis após analisar os termos tradição, alimentos tradicionais e alimentos artesanais, discussão também desenvolvida na primeira seção. Na segunda seção, o artigo explora dados oriundos dos principais regulamentos federais que constituem o marco regulatório sanitário para o processamento de alimentos no Brasil, buscando não apenas identificar avanços e retrocessos para a legalização sanitária de agroindústrias familiares, mas também analisar em que medida os regulamentos vigentes respondem à realidade e às características do processamento tradicional de alimentos.

\section{Processamento de alimentos e agricultura familiar: características e definições}

O processamento de alimentos por famílias rurais, longe de ser uma prática nova, é uma atividade que, historicamente, compõe a lógica de funcionamento da agricultura familiar (Mior, 2005). Nesse sentido, como também argumentam Wilkinson et al. (2017), ao se referirem aos produtos coloniais e, em especial, aos queijos coloniais produzidos no sul do Brasil $^{4}$, o processamento de alimentos, feito principalmente pelas mulheres como uma extensão das atividades da cozinha, voltava-se ao consumo doméstico.

No que tange ao processamento de alimentos, nas últimas décadas foi possível observar crescente organização e formalização do setor, evidenciando acentuado deslocamento das atividades de processamento do espaço doméstico, na cozinha, para o de uma agroindústria, processo bastante incentivado e estudado no Brasil (Gazolla, 2013; Pellegrini \& Gazolla, 2008; Cruz, 2007; Sgarbi dos Santos, 2006; Mior, 2005; Prezotto, 2005).

\footnotetext{
${ }^{4}$ Dorigon (2008), em tese de doutoramento em que se propôs a analisar os mercados de produtos coloniais da região oeste do estado de Santa Catarina, define produtos coloniais como "[...] um conjunto de produtos tradicionalmente processados no estabelecimento agrícola pelos agricultores - os 'colonos' - para o autoconsumo familiar, tais como salames, queijos, doces e geleias, conservas de hortaliças, massas e biscoitos, açúcar mascavo, dentre outros" (Dorigon, 2008, p. 1). Os "colonos", responsáveis pela produção desses alimentos, como define o mesmo autor, são agricultores descendentes de imigrantes europeus, particularmente de origens italiana e alemã, que, depois de inicialmente se instalarem na Serra do Rio Grande do Sul, migraram, no século XX, para a região oeste de Santa Catarina, constituindo as "colônias", termo que faz referência à estrutura fundiária que orientou a colonização das terras ocupadas pelos imigrantes.
} 
Porém, apesar desse deslocamento, as atividades de processamento continuam sendo realizadas, no caso de muitas famílias rurais, nas cozinhas ou em espaços que se constituem como extensão destas. Mas, diferentemente do caso de agroindústrias familiares, amplamente estudadas, o processamento nesses espaços é, em boa medida, pouco conhecido ou estudado.

Assim, de algum modo, podemos entender que as iniciativas para a agroindustrialização se constituíram em esforço para formalização ${ }^{5}$. Para Mior (2005), "[...] a agroindústria familiar rural não se resume ao processamento de alimentos e matérias-primas. Embora o processamento faça parte de toda agroindústria familiar rural, esta é mais abrangente e possui características que a distinguem" (Mior, 2005, p. 191). Para o autor, enquanto as agroindústrias familiares rurais dizem respeito a uma forma e a uma lógica de organização da agricultura familiar que visa produzir e processar parte de sua produção agropecuária para a comercialização, a atividade de processamento de alimentos e matérias-primas volta-se principalmente para o abastecimento das famílias produtoras, ou seja, para o autoconsumo. Segundo o autor,

Enquanto o processamento e a transformação de alimentos ocorrem geralmente na cozinha das agricultoras, a agroindústria familiar rural se constitui em um novo espaço e em um novo empreendimento social e econômico. A atividade artesanal de transformação de alimentos, sobretudo da mulher agricultora, evidencia ainda a existência de aspectos culturais associados aos hábitos alimentares de uma determinada região (Mior, 2005, p. 191).

No que se refere às características de funcionamento de agroindústrias familiares, o mesmo autor destaca a localização no meio rural, a utilização de máquinas e equipamentos em escalas menores, a procedência própria da matéria-prima (ou, em menos quantidade, de vizinhos), processos artesanais próprios e a mão de obra familiar. Nesse mesmo sentido, Silveira \& Heinz (2005) destacam que, nesse tipo de processamento, para além da técnica, há uma dimensão artística que torna cada produto artesanal único, característico de cada produtor ou produtora.

Outra característica importante é a diversidade da produção. Como analisam Craviotti \& Palacios (2014) em relação a formas de comercialização adotadas por fruticultores familiares do nordeste da província de Buenos Aires, Argentina, os que permanecem na atividade são "precisamente aquellos que han podido diversificar sus producciones y canales de comercialización" (Craviotti \& Palacios, 2014, p. S076). Os dados apontados pelas autoras trazem evidências que permitem confirmar também a realidade da produção e do processamento de alimentos por agricultores familiares no contexto brasileiro.

Considerando essas características, entendemos que os alimentos processados no âmbito de agroindústrias familiares e aqueles que continuam sendo processados no espaço doméstico ou contíguo à casa têm características comuns, mas não necessariamente se tratam dos mesmos produtos. Nessa distinção, Mior (2005, p. 191) argumenta que “[...] outra dimensão importante é que a agroindústria familiar está crescentemente internalizando os aspectos legais, tanto do ponto de vista sanitário como ambiental e fiscal, perante os organismos de regulação pública".

Mas, se para as agroindústrias familiares há definições e características consensuais, o mesmo não acontece em relação ao processamento tradicional dos alimentos que, como já evidenciado, é muito expressivo, mas, ao mesmo tempo, bastante invisibilizado. De certo

\footnotetext{
${ }^{5}$ Nesse sentido, cabe crítica que encontra alguma ressonância entre defensores e militantes de alimentos artesanais, os quais questionam inclusive o termo agroindústria. Buscando analisar tal crítica, é possível encontrar elementos para reflexão no fato de que o processo de consolidação de agroindústrias no Brasil se dá em decorrência do processo de modernização da agricultura ou, como explica Graziano da Silva (1996), da transição do complexo rural aos complexos agroindustriais (CAls). Nessa transição, o desenvolvimento de mercado interno no capitalismo tem como elementos fundamentais a transformação da agricultura em indústria, a produção de mercadorias especializadas, a agricultura subordinada ao capital e a integração da agricultura à grande agroindústria (Graziano da Silva, 1996).
} 
modo, tal invisibilidade pode ser compreendida segundo o entendimento de que esses produtos feitos informalmente nos espaços domésticos possuem mais valor de uso do que valor de troca, como sugere Mior (2005). Porém, se a produção desses produtos for entendida não como voltada à subsistência da família, mas sim como produção para o autoconsumo, ou seja, produção que visa abastecer a família, mas que também e intencionalmente está organizada para produzir excedentes (Grisa, 2007), ao serem comercializados, como também evidencia a pesquisa de Bigheline da Silveira (2013), esses alimentos terão valor de troca. Desse modo, é importante destacar que, ainda que produzidos em pequena escala, esses produtos podem ser entendidos dentro da lógica familiar segundo outra perspectiva, qual seja a de produtos que têm duplo papel e relevância: possuem valor de uso e de troca.

Nesse sentido, mais do que perceber o imenso contingente de famílias rurais que processam e comercializam alimentos de modo informal como potenciais agroindústrias familiares, é válido analisar essas famílias considerando que, temporária (se não definitivamente), a informalidade é uma opção. Essa interpretação encontra ressonância em Varga (2017) que, ao se referir ao contexto de distintas regiões da Ucrânia e da Romênia no período pós-comunismo, discute as características e possibilidades dos agricultores dessas regiões se inserirem em mercados formais. $\mathrm{O}$ autor argumenta que há sobreposição entre informalidade e a ideia de "tradicional" e entre formalidade e a ideia de "moderno", e, em relação ao "moderno", associam-se também padrões de qualidade e segurança dos produtos. Porém, como problematiza Varga (2017), a literatura sobre o tema provavelmente subestima a influência de interesses pessoais de atores econômicos na existência da economia informal que, mais do que uma "armadilha da pobreza", como discute Maloney (2003), se constitui em um "complexo conjunto de arranjos e práticas não contratuais que permitem aos participantes dessa economia sobreviver apesar da ampliação do setor formal" (Varga, 2017, p. 59).

A análise de Varga (2017) contribui para que, retomando o debate sobre a informalidade presente no setor de processamento de alimentos no Brasil, a discussão seja um pouco mais aprofundada. Nesse sentido, a ideia lastro a ser desenvolvida se sustenta na relação tradicional-informal, que pode ser repensada de modo que, em vez de informal enquanto atributo inerentemente negativo, que remete a atraso e desqualificação produtiva, sistemas alimentares tradicionais sejam analisados como mercados fragmentados.

Contribuindo nessa análise, Lee et al. (2012) propõem um modelo para investigar como, por meio de padrões impostos (incluindo segurança e qualidade), cadeias de valor afetam produtores de pequena escala. Os autores consideram a adoção de standards privados na análise do papel e da posição de pequenos produtores em cadeias agroalimentares, argumentado que estas variam de acordo com o tipo de cadeia, mas, de todo modo, destacam que, para além do dualismo que emerge entre produção industrializada em larga escala e produção fundamentada na pequena produção, tal inserção está para além de simples inclusão ou exclusão, reforçando o argumento de que, muito mais do que a relação aparentemente inerente entre produção tradicional com informalidade ou, ainda, com os obstáculos que separam sistemas tradicionais de modernos, é a fragmentação dos mercados que, de forma mais adequada, pode descrever a inserção da produção tradicional no mercado.

Em síntese, retomando as reflexões de Varga (2017), "mercados tradicionais", entendidos como mercados fragmentados, consistem em número expressivo de produtores e de varejistas, geralmente operando em pequena escala, com pouca demanda explícita e coordenação para o abastecimento, mas, apesar disso, de modo geral, bastante eficientes.

Para o caso do processamento de alimentos no âmbito da agricultura familiar, à luz dos argumentos de Varga (2017), podemos entender esses produtos operando principalmente em mercados tradicionais que podem ser entendidos não como informais, mas como fragmentados. Essa discussão certamente pode ser ampliada com base em autores que, a exemplo de Triches (2010), Agne \& Waquil (2011) e Gazolla (2013), têm pesquisado sobre mercados construídos socialmente e, de modo geral, ao dialogarem com autores da sociologia econômica, têm enfatizado a importância do enraizamento social para a construção e 
manutenção de mercados para produtos da agricultura familiar. Embora esse debate não seja o foco deste artigo, é importante mencionar que a relação e a discussão entre autores que discutem sob essa perspectiva podem ser aprofundadas em estudos futuros.

No que se refere aos produtos tradicionais em relação aos considerados modernos, cabe retomar a reflexão de Wilkinson \& Mior (1999) que, apesar de ter sido feita há quase 20 anos, continua atual. Os autores argumentam que o modelo adotado para a produção de alimentos no Brasil, fortemente alicerçado na ciência e na tecnologia, é, exatamente pela relação entre ciência e tecnologia, considerado moderno. Essa concepção, que associa processamento industrial a modernidade, incute na sociedade um padrão de higiene e inocuidade que pressupõe que qualquer sistema de produção de alimentos que não atenda a tal padrão seja tratado como ameaça à saúde dos consumidores, contribuindo fortemente para que o processamento tradicional de alimentos, em vez de receber apoio para ser qualificado e valorizado, seja invisibilizado e, assim, continue na informalidade.

De todo modo, nesse debate, tanto no que se refere aos mercados informais como, principalmente, no que diz respeito às agroindústrias formalizadas, a inserção de produtos no mercado é, em grande medida, decorrência da valorização crescente do atributo "tradição", comum em qualquer um dos casos. Contudo, no que se refere ao processamento de alimentos, como definir tradição? Antes de avançarmos nessa direção, cabe ter presente que, em relação aos alimentos produzidos no âmbito da agricultura familiar, em geral, além de tradição, o adjetivo artesanal também é central. Tendo em vista a centralidade desses dois conceitos, na seção a seguir busca-se explorar uma possível definição para eles, tendo como baliza o entendimento de produtos agroalimentares. Para esse trajeto, conforme proposto por Cruz (2012), o ponto de partida é a noção de tradição, tomada das contribuições de Giddens (1997) para, com base nelas, propor elementos para definir produção tradicional e produção artesanal de alimentos que, embora fortemente imbricadas, não podem ser tomadas como sinônimos.

\section{Produtos agroalimentares tradicionais e artesanais: uma primeira definição é possivel?}

Para apreender a noção de tradição e avançarmos em direção a uma definição de produção tradicional de alimentos e de alimentos tradicionais, como proposto por Cruz (2012), procuramos elementos na discussão sobre a sociedade pós-tradicional ou da alta modernidade, explorada por Giddens (1997). Essa discussão encontra respaldo no processo de valorização de alimentos e espaços rurais, discutido por diversos autores, como Menasche (2010), Eizner (1995), Cristóvão (2002) e Kneafsey et al. (2008) que, com mais ou menos expressão, vinculam esse processo também à idealização ou à romantização do rural. Esse cenário pode ser analisado por meio de elementos oferecidos por Giddens (1997), na discussão sobre tradição na modernidade e, particularmente, na alta modernidade. Para o autor, é na passagem para a modernidade e a alta modernidade que a tradição é dissolvida, a natureza é invadida e transformada e imprevisibilidades e incertezas sobre o futuro - construídas com avanços tecnológicos - constituem-se em elementos com os quais a humanidade passa a conviver.

A natureza assume, então, papel interessante, pois "o que é 'natural' é o que permanece fora do escopo da intervenção humana" (Giddens, 1997, p. 96). Seguindo esse raciocínio, a natureza é vista como independente da atividade humana e assume significado de "campo", espaço que entra em contraste com a cidade e, muito frequentemente, tem a conotação de uma cena idílica rural. Essa imagem, como argumenta o autor, é

[...] absolutamente falsa, pois o campo é a natureza subordinada aos planos humanos", embora o mesmo autor pondere que "[...] a 'natureza' neste sentido realmente preserva traços há muito tempo associados à sua separação da intervenção humana (Giddens, 1997, p. 97, grifos do autor ).

O fim da natureza é, como proposto pelo mesmo autor, sua completa socialização e, diante dessa ameaça, a busca pela tradição associa-se à adoção de novos estilos de vida, 
especialmente não ocidentais, embora "[...] nenhuma tentativa para reanimar a natureza vai reintroduzir a natureza como ela era anteriormente" (Giddens, 1997, p. 99).

Ainda que a tradição ou a revalorização da tradição não seja capaz de reintroduzir a natureza como ela foi outrora, movimentos de retorno ao "campo", pautados por uma idealização do rural, como considerado por Menasche (2003) e Eizner (1995), ou pela nostalgia, nos termos de Kneafsey et al. (2008), parecem oferecer certo conforto. A valorização do rural pode ser entendida, portanto, em termos da possibilidade de valorizar um tempo em que não havia riscos ou, ao menos, em que os riscos não eram fabricados ou imprevisíveis.

Essa busca por segurança e conforto dá-se também em relação a alimentos que, como discutido por vários autores, têm sido crescentemente valorizados por atributos associados ao natural, que remetem a uma época em que os gêneros alimentícios eram produzidos no ambiente doméstico e, assim, conhecidos. Atualmente, distantes do local e origem de produção e processamento dos alimentos, os consumidores presenciam sucessivos casos de contaminação de alimentos. A romantização do rural ${ }^{6}$, associada à ideia de alimentos naturais, assume, gradativamente, mais importância. É nesse contexto que tomamos elementos apontados por Giddens para propor significados associados não apenas à produção tradicional de alimentos, mas também aos próprios alimentos tradicionais e às suas interfaces com o natural e o artesanal.

Seguindo tal perspectiva, seja por considerar que "a modernidade, quase por definição, sempre se colocou em oposição à tradição" (Giddens, 1997, p. 73) ou, talvez, por considerar - ainda que ponderando que a tradição foi fundamental nas primeiras fases da modernidade - que "a modernidade destrói a tradição" (Giddens, 1997, p. 113) é que o autor discute a noção de tradição. Nos termos propostos por ele, a tradição é marcada por caráter repetitivo, o que indica conotação temporal. De acordo com esse raciocínio, a tradição tem relação com o tempo. Assumindo tal relação, segundo Giddens,

[...] a tradição é uma orientação para o passado, de tal forma que o passado tem uma pesada influência ou, mais precisamente, é constituído para ter uma pesada influência sobre o presente. Mas evidentemente, em certo sentido e em qualquer medida, a tradição também diz respeito ao futuro, pois as práticas estabelecidas são utilizadas como maneira de se organizar o tempo futuro. O futuro é modelado sem que se tenha a necessidade de esculpi-lo como um território separado. A repetição, de uma maneira que precisa ser examinada, chega a fazer o futuro voltar ao passado, enquanto também aproxima o passado para reconstruir o futuro. (Giddens, 1997, p. 80).

O caráter repetitivo da tradição não significa, contudo, que as tradições sejam estáticas, que não sofram mudanças ou alterações ao longo do tempo. Apesar disso, a noção de tradição pressupõe persistência e, por isso, crenças e práticas apresentam integridade e continuidade que, segundo o mesmo autor, resistem às mudanças. As tradições se desenvolvem e amadurecem ou enfraquecem e "morrem", por isso a integridade de uma tradição, compreendida não simplesmente como refratária ao tempo, mas sim como processo contínuo de interpretação que permite estabelecer ligações entre presente e passado, é mais importante para defini-la como tal do que seu tempo de existência.

Trazendo a discussão proposta por Giddens sobre tradição para pensar os alimentos, pode-se argumentar que práticas de produção e preparação de alimentos em muitos contextos rurais seguem modos de fazer rituais, conduzidos por produtores que detêm conhecimento e reputação necessários para manter a produção. Nesses contextos, pode ser mais frutífero pensar em modos de produção que envolvem não apenas o alimento, produto final, mas todo o processo que, desde a origem das matérias-primas, modos de

${ }^{6}$ Para excelente e arejada discussão que apresenta os limites da romantização do rural, veja Tregear (2011). 
produzir, armazenar, consumir etc., procura nutrir, no presente, os laços que ligam o passado ao futuro.

A interpretação da tradição, no caso dos alimentos, poderia levar a adaptações que envolvem facilidades no processamento, o que, muitas vezes, inclui a inserção de elementos "modernos", como utensílios e ingredientes. Contudo, essas interpretações ou alterações não implicam necessariamente que a tradição esteja se perdendo, pois, ainda seguindo a linha de argumentação de Giddens (1997), não é a repetição exata que garante a tradição, mas sim as interpretações pelas quais ela passa, muitas vezes necessárias para manter o passado conectado ao presente e ao futuro.

Nesse sentido, Delfosse (1995), ao se referir ao contexto francês, pondera que os queijos seriam um bom exemplo de alimento que se coloca entre a tradição e a modernidade. Para essa autora, a tradição estaria vinculada ao consumo de queijo, que se mantém como um forte hábito pelo fato de ser um produto típico, possuir especialidade local e estar vinculado a uma região de origem, ser produzido de acordo com técnicas de produção particulares e savoir-faire transmitido de geração em geração. Já a modernidade estaria associada não apenas à tendência de adaptação às novas demandas dos consumidores, principalmente em relação a mudanças nas práticas alimentares e nas embalagens dos queijos, na mecanização, automatização e inovações técnicas, de modo a produzir queijos com forma e gosto regulares e facilmente transportáveis, mas também à ideia de produtos limpos, feitos com higiene perfeita.

Para a mesma autora, os produtores de alguns queijos - ditos tradicionais - aliam tradição e modernidade não só na medida em que atendem a regulamentos sanitários, mas também na medida em que alteram a qualidade do leite em decorrência da seleção e mudanças na alimentação dos animais. Outro elemento que integra tradição e modernidade, de acordo com a análise de Delfosse (1995), é o fato de que, cada vez mais, queijos ditos tradicionais são vendidos pré-embalados e, em alguns casos, adaptados à demanda por queijos com menos teor de gordura, por exemplo. Nesse sentido, a autora avalia que a modernização passa a ser um dos meios adotados para que os queijos tradicionais não sejam condenados pela evolução do consumo, das práticas de compra e pela necessidade de baixar os custos de produção, mas, sobretudo, pela evolução das regulamentações sanitárias.

Em relação aos alimentos de modo geral, Garcia (2003), ao analisar os reflexos da globalização na cultura alimentar no Brasil, considera que, como parte da mundialização da cultura, o significado de "tradição" apresenta dois sentidos distintos: "tradição enquanto permanência do passado distante" (mundo anterior à Revolução Industrial) e "tradição da modernidade", como uma tradição reinventada, a qual recicla elementos da memória internacional popular, recriando e atualizando elementos do passado que se misturam com o presente. Para essa autora, a valorização do tradicional associa valores vinculados à natureza, à terra, à origem rural e a uma suposta identificação com o "autêntico" e o "puro". "É justamente quando cresce a utilização de produtos industrializados que o argumento 'tradição' ganha mais destaque. Essa busca pela tradição se enquadra perfeitamente na noção de 'tradição da modernidade'"' (Garcia, 2003, p. 491, grifos no original).

Com base nos argumentos de Giddens (1997) e também nos de Delfosse (1995) e Garcia (2003), pode-se tomar como central para pensar uma definição de alimentos tradicionais o caráter repetitivo da tradição - que não implica, contudo, que não haja mudanças nem alterações, as quais são necessárias até mesmo para interpretar e, assim, manter a tradição ativa. Contextos em que técnicas pré-modernas de produção de alimentos têm sido mantidas, algo no sentido do que Garcia considera "tradição enquanto permanência do passado distante", podem ser consideradas situações pouco prováveis ou, no mínimo, pouco comuns. Porém, para além dessas situações, poderíamos considerar tradicionais também modos de produção que, seguindo um modo de fazer aprendido com gerações anteriores, mantêm características da produção e processamento que, embora mais ou menos alteradas, conservam elementos e práticas ensinadas por gerações anteriores. O resultado seria, do mesmo modo, a produção de alimentos tradicionais. 
Como já apontado, a definição de produtos agroalimentares tradicionais implica também discutir artesanalidade, característica central e frequentemente associada a alimentos tradicionais. Nesse intuito, no que se refere a alimentos, a artesanalidade está fortemente vinculada à noção de tradição. Podemos sustentar essa afirmação argumentando que a ideia de tradição remete, como já mencionou Garcia (2003), ao mundo anterior à Revolução Industrial, em que os processos, visíveis e conhecidos tanto no que diz respeito a ingredientes quanto a etapas de produção, eram manuais e marcados pela não padronização dos produtos e pela baixa (ou inexistente) mecanização do processo. Naquele contexto, não havia divisão social do trabalho e a produção de alimentos era realizada, em sua maioria, pelas próprias famílias, que detinham o conhecimento e todos os meios de produção, de ferramentas para a produção de matéria-prima até utensílios para o processamento e elaboração dos produtos finais.

Assumindo essa concepção de artesanal, é possível argumentar que alimentos considerados tradicionais vinculam-se aos artesanais na medida em que, ao seguir um saber-fazer tradicional, adotam modos de produzir que tiveram suas técnicas de produção estabelecidas há um tempo significativamente longo, quando não se dispunha de mecanização nem/ou técnicas automatizadas de produção. Apesar de realizar alterações e adaptações, em geral, a maioria dos(as) produtores(as) preserva grande parte das características do modo de fazer ensinado por gerações anteriores. Mas, diferentemente de alimentos que remetem a uma tradição, há alimentos artesanais, produzidos em pequena escala, sem automatização de processos, que não necessariamente tiveram seus processos de produção estabelecidos há séculos, ou seja, que essencialmente não possuem saberfazer tradicional, podendo ser, portanto, considerados artesanais, mas não necessariamente tradicionais.

Tradicionais ou não, alimentos considerados artesanais têm merecido a atenção tanto de consumidores como de produtores. A busca por alimentos desse tipo artisanal reaction, como se referem Murdoch \& Miele (2004) - apresenta-se em um contexto em que a valorização de alimentos feitos por meio de processos mais naturais, como, em geral, credita-se a alimentos locais, tradicionais, orgânicos, tem se tornado crescentemente difundida. De fato, em um contexto em que estão presentes recorrentes casos de contaminação de alimentos, os consumidores buscariam segurança por meio do consumo de alimentos conhecidos que, diferentemente daqueles produzidos e processados de modo altamente intensivo e sem local de origem definido (placeless in origin), ofereceriam garantias sobre seus produtores, ingredientes e modo de processamento (Murdoch \& Miele, 1999, 2004). Por essa razão, retomando aqui a argumentação de Giddens (1997), na alta modernidade, em que os riscos produzidos pela tecnologia passam a ser ameaça fabricada e imprevisível com a qual a população começa a conviver, atributos relacionados à produção local e à origem reconhecida se constituem em aspectos crescentemente desejáveis e valorizados e, até mesmo, idealizados nos alimentos.

Do ponto de vista dos produtores, o reconhecimento da artesanalidade ou da arte da artesanalidade, como um atributo a ser considerado e valorizado, pode ser analisado à luz de análises como as de Ploeg (2008) que, ao discutir sobre mecanismos de recampenização e formas de proporcionar autonomia aos agricultores - ou campesinos, como se refere o autor -, enfatiza a centralidade da diversificação de processos produtivos e de produtos, bem como a construção de novos circuitos de comercialização como forma de enfrentar grandes mercados. Para o autor, a reintrodução da artesanalidade “[...] está associada ao desenvolvimento e implementação de uma nova geração de tecnologias orientadas para habilidades e resulta, muitas vezes, na produção contínua de novidades" (Ploeg, 2008, p. 175). As reflexões de Ploeg são relevantes, mas, considerando o caso de países como o Brasil, que tiveram processo de modernização parcial da agricultura, é interessante considerar que seria mais adequado falar de valorização da artesanalidade do que de reintrodução da artesanalidade, perspectiva que se soma à análise de Fonte (2008, 2010) e de Cruz (2012). 
A discussão desenvolvida nesta seção busca dar sustentação ao argumento central nesta análise: há diferenças importantes entre agroindústrias familiares e o processamento tradicional de alimentos. Nessa discussão, é fundamental apreender que, no caso do processamento tradicional, a lógica subjacente diz respeito à forma como historicamente os alimentos são processados pelas famílias rurais, característica que, ao mesmo tempo que confere singularidade aos produtos, coloca-os em situação de informalidade. Essa distinção e discussão são relevantes e merecem ser ampliadas na medida em que negligenciar a amplitude dessa forma de processamento, bem como o histórico dessas atividades pela agricultura familiar, não contribui para a qualificação desses produtos nem, consequentemente, para o trabalho das famílias rurais e, nesse caso, especialmente o trabalho feminino. Ainda que sem pretensão de esgotar esse debate e as possibilidades para legitimar o processamento tradicional de alimentos, o propósito que guia a continuidade deste artigo diz respeito à compreensão do ambiente institucional, especialmente no que se refere aos regulamentos sanitários aos quais alimentos processados pela agricultura familiar estão sujeitos.

Nesse sentido, a próxima seção volta-se ao marco regulatório sanitário que baliza o processamento de alimentos no Brasil, buscando, por um lado, identificar avanços e retrocessos em regulamentos que incidem sobre agroindústrias familiares e, por outro, analisar em que medida tais regulamentos respondem não apenas à realidade e às características das agroindústrias familiares, mas também às possibilidades de convergência à realidade do processamento tradicional de alimentos e ao processamento de produtos agroalimentares artesanais.

\section{Marco regulatório sanitário no Brasil: avanços e retrocessos para o processamento de alimentos pela agricultura familiar}

No final da década de 1990 e início dos anos 2000, o Brasil assistiu a um amplo processo de reconhecimento e de estímulo à produção e ao processamento de alimentos pela agricultura familiar (Mior, 2005; Wesz Junior, 2010). Especificamente no que se refere ao processamento de alimentos, entre as principais ações que merecem destaque, está a incorporação, em 1998, de uma linha de crédito para investimentos em agroindústrias familiares. Trata-se da política de Agregação de Renda à Atividade Rural (Pronaf-Agregar) que, em 2003, alinhada ao Programa de Agroindustrialização da Produção dos Agricultores Familiares, passou a se chamar Pronaf-Agroindústria (Wesz Junior, 2010) ${ }^{7}$. Naquele contexto, iniciativas como a assentada no programa federal, voltadas a viabilizar agroindústrias familiares, tinham como justificativa não apenas a construção de alternativas econômicas para a permanência dos agricultores familiares no meio rural, mas, para além disso, a construção de um novo modelo de desenvolvimento sustentável, atribuindo ao meio rural não só a produção agrícola, mas também oportunidades de inclusão e engajamento social e resgate de valores sociais e culturais (Cruz, 2007; Cruz, Schneider, 2010). Com base nessas audaciosas expectativas, essa articulação visava, como argumenta Wesz Junior (2010), além de financiamento, também ao apoio às agroindústrias no que diz respeito à legislação, à adaptação de tecnologias e ao acesso aos mercados.

Porém, como considera Deon (2015, p. 41), "[...] as políticas públicas ainda têm sido pouco efetivas no sentido de promover a agroindustrialização como uma fonte importante na composição da renda para a agricultura familiar". Entre os aspectos relacionados a pouca efetividade citada, cabe menção aos limites relacionados aos regulamentos sanitários. Nesse sentido, particularmente no que diz respeito à legislação incidente sobre o processamento de alimentos, no contexto em que os primeiros programas voltados a essa atividade agrícola começaram a surgir no Brasil, surgiram também debates em torno da adequação das normas

${ }^{7}$ Para discussão mais ampla sobre políticas voltadas a agroindústrias familiares em âmbito nacional e de alguns estados brasileiros, veja Wesz Junior (2010). 
sanitárias, fiscais/tributárias e ambientais então vigentes para a industrialização de alimentos ${ }^{8}$. Naqueles debates, o argumento principal estava relacionado ao fato de que as normas que as agroindústrias familiares deveriam seguir em nada se diferiam daquelas estabelecidas para 0 processamento de alimentos em larga escala, estabelecidas no âmbito e na lógica da formação dos complexos agroindustriais. Como argumentou Prezotto (2005), o ambiente institucional daquele momento, principalmente no que se referia à legislação sanitária, era inadequado à legalização de agroindústrias rurais de pequeno porte.

Naquele momento, uma primeira discussão que emergiu e tomou amplitude esteve fortemente vinculada à necessidade de "flexibilização" da legislação, para que, assim, o processamento familiar de alimentos pudesse ser legalizado. À época, a discussão que orientava os esforços para viabilizar normas mais alinhadas à realidade, características e escala de produção do processamento de alimentos pela agricultura familiar estruturaram suas críticas principalmente no fato de a legislação sanitária de alimentos ter sido publicada na década de 1950, momento em que se estruturavam, no Brasil, os complexos agroindustriais (Graziano da Silva, 1996), balizados pela produção e processamento em larga escala. Como caso emblemático e mais discutido está o Regulamento da Inspeção Industrial e Sanitária de Produtos de Origem Animal (RIISPOA), primeira regulamentação relacionada à inspeção de alimentos de origem animal, que entrou em vigor em 1952, por meio do Decreto no 30.691, que aprovou o Regulamento da Inspeção Industrial e Sanitária de Produtos de Origem Animal (RIISPOA), estabelecido pela Lei no 1.283, de dezembro de 1950 (Brasil, 1950, 1952) . Muitas das críticas que recorrentemente estão vinculadas à exigência de superdimensionamento de agroindústrias familiares - como necessidade de banheiros feminino, masculino e para fiscais da inspeção, apenas para citar um exemplo encontram amparo nesse regulamento que, inquestionavelmente, estava alinhado à realidade de grandes agroindústrias.

Nesse sentido, vale ter presente que, à época da publicação da primeira edição do RIISPOA, não significava que não havia processamento de alimentos no âmbito da agricultura familiar, pelo contrário. Como já argumentado, essa atividade é historicamente realizada pelas famílias rurais, mas, como é feita em pequena escala e, ainda mais do que hoje, como naquele contexto não parecia ser objetivo primeiro comercializar essa produção, não foi reconhecida nem contemplada na criação do primeiro marco regulatório para a inspeção de alimentos. Nesse sentido, cabe retomar a distinção proposta por Wilkinson \& Mior (1999), já referida neste artigo. Os autores, considerando o caso de setor lácteo no Brasil, argumentam que, até a década de 1950, não existia regulamentação do setor primário para normatizar as diversas etapas da produção, de modo que não era possível falar em setor informal. Apenas a partir da publicação do regulamento de inspeção para produtos de origem animal, no início da década de 1950, a produção até então historicamente realizada pelas famílias rurais passou para o âmbito do setor formal, o que levou, indiretamente, o processamento tradicional de alimentos para a informalidade (Wilkinson \& Mior, 1999). O RIISPOA foi o primeiro regulamento brasileiro voltado à formalização do processamento de alimentos. Esse Regulamento foi revisado e, em 2017, uma versão atualizada foi publicada (Brasil, 2017a). Além do RIISPOA, outros regulamentos de vigência nacional, que são importantes por incidirem sobre amplo espectro de alimentos, estão sistematizados na Tabela 1 e serão analisados ao longo desta seção ${ }^{10}$.

\footnotetext{
${ }^{8}$ Além de questões sanitárias relativas à legalização de agroindústrias familiares, também é importante analisar aspectos ambientais e fiscais/tributários, de modo que, embora a presente análise volte-se apenas à questão sanitária, cabe frisar que outros estudos sobre os demais aspectos são necessários e igualmente pertinentes.

${ }^{9}$ Esse regulamento foi revisado e atualizado e um "novo" RIISPOA foi publicado em 2017 (Brasil, 2017a). Mas, do mesmo modo que o regulamento da década de 1950, o desenho da versão atual continua voltado ao processamento em larga escala.

${ }^{10}$ Além dos regulamentos indicados na Tabela 1, existem outros regulamentos nacionais e estaduais importantes, como será mencionado no texto. Porém, a Tabela restringe-se a regulamentos de abrangência nacional, que, além de serem mais amplos, apresentam singularidades que merecem atenção.
} 
Tabela 1. Regulamentos sanitários relevantes para o contexto do processamento de alimentos pela agricultura familiar no Brasil

\begin{tabular}{|c|c|c|c|}
\hline Regulamento & Autor/Ano & Publicação & Descrição \\
\hline $\begin{array}{l}\text { Regulamento e } \\
\text { Inspeção Industrial e } \\
\text { Sanitária de produtos } \\
\text { de Origem Animal } \\
\text { (RIISPOA) Constituído } \\
\text { por meio da Lei } \\
\text { no } 1.283 \text {, de dezembro } \\
\text { de } 1950\end{array}$ & $\begin{array}{l}\text { Brasil } \\
(1950)\end{array}$ & $\begin{array}{l}\text { Presidência da } \\
\text { República } \\
\text { Casa Civil }\end{array}$ & $\begin{array}{l}\text { Primeira regulamentação relacionada à inspeção de } \\
\text { alimentos de origem animal }\end{array}$ \\
\hline $\begin{array}{l}\text { Decreto no } 30.691, \text { de } \\
\quad \text { março de } 1952\end{array}$ & $\begin{array}{l}\text { Brasil } \\
(1952)\end{array}$ & $\begin{array}{l}\text { Presidência da } \\
\text { República } \\
\text { Casa Civil }\end{array}$ & $\begin{array}{l}\text { Aprovava o Regulamento da Inspeção Industrial e } \\
\text { Sanitária de Produtos de Origem Animal (RIISPOA) } \\
\text { Foi revogado pelo Decreto № 9.013, de } 2017 \text { (citado } \\
\text { abaixo) }\end{array}$ \\
\hline $\begin{array}{l}\text { Lei } n \text { o } 7.889 \text {, de } 23 \text { de } \\
\text { novembro de } 1989\end{array}$ & $\begin{array}{c}\text { Brasil } \\
(1989)\end{array}$ & $\begin{array}{l}\text { Presidência da } \\
\text { República } \\
\text { Casa Civil }\end{array}$ & $\begin{array}{l}\text { Complementarmente ao Decreto ํo } 30.691 \text { e a } \\
\text { Lei № } 1.283 \text {, dispõe sobre inspeção sanitária e industrial } \\
\text { dos produtos de origem animal }\end{array}$ \\
\hline $\begin{array}{l}\text { Sistema Unificado de } \\
\text { Atenção à Sanidade } \\
\text { Agropecuária (SUASA) } \\
\text { Constituído por meio } \\
\text { da Lei no } 9.712 \text {, de } \\
\text { novembro de } 1998 \\
\text { (artigos } 27,28 \text { e 29) } \\
\text { constituiu o SUASA }\end{array}$ & $\begin{array}{c}\text { Brasil } \\
(1998)\end{array}$ & $\begin{array}{l}\text { Presidência da } \\
\text { República } \\
\text { Casa Civil }\end{array}$ & $\begin{array}{l}\text { O Sistema Unificado de Atenção à Sanidade Agropecuária } \\
\text { (Suasa) se constitui em nova proposta de sistema de } \\
\text { inspeção, organizado de forma unificada, descentralizada } \\
\text { e integrada entre a União que, por meio do Ministério da } \\
\text { Agricultura, Pecuária e Abastecimento, coordena o } \\
\text { sistema, que tem como Instância Central e Superior a } \\
\text { União, os estados e Distrito Federal, como Instância } \\
\text { Intermediária, e os municípios, como Instância Local }\end{array}$ \\
\hline $\begin{array}{l}\text { Decreto no } 5.741 \text {, de } \\
\quad \text { março de } 2006\end{array}$ & $\begin{array}{l}\text { Brasil } \\
(2006)\end{array}$ & $\begin{array}{l}\text { Presidência da } \\
\text { República } \\
\text { Casa Civil }\end{array}$ & $\begin{array}{l}\text { Regulamenta e organiza o Sistema Unificado de Atenção à } \\
\text { Sanidade Agropecuária (Suasa) }\end{array}$ \\
\hline $\begin{array}{l}\text { Resolução-RDC no 49, } \\
\text { de outubro de } 2013\end{array}$ & $\begin{array}{l}\text { Brasil } \\
(2013)\end{array}$ & $\begin{array}{l}\text { Ministério da } \\
\text { Saúde/Agência } \\
\text { Nacional de } \\
\text { Vigilância } \\
\text { Sanitária }\end{array}$ & $\begin{array}{l}\text { Dispõe sobre a regularização para o exercício de atividade } \\
\text { de interesse sanitário do microempreendedor individual, } \\
\text { do empreendimento familiar rural e do empreendimento } \\
\text { econômico solidário, fazendo referência à inclusão } \\
\text { socioprodutiva com segurança sanitária dos alimentos }\end{array}$ \\
\hline $\begin{array}{l}\text { Decreto } \mathrm{n}^{\circ} 8.471 \text {, de } \\
\quad \text { junho de } 2015\end{array}$ & $\begin{array}{c}\text { Brasil } \\
(2015 a)\end{array}$ & $\begin{array}{l}\text { Presidência da } \\
\text { República } \\
\text { Casa Civil }\end{array}$ & $\begin{array}{l}\text { Altera o Anexo ao Decreto no } 5.741 \text {, março de } 2006 \text {, e } \\
\text { organiza o Sistema Unificado de Atenção à Sanidade } \\
\text { Agropecuária, reconhecendo a agroindustrialização } \\
\text { realizada pela agricultura familiar ou equivalente e suas } \\
\text { organizações, inclusive quanto às condições estruturais e } \\
\text { de controle de processo. }\end{array}$ \\
\hline $\begin{array}{l}\text { Instrução Normativa no } \\
\text { 16, de junho de } 2015 \\
\text { (IN16) }\end{array}$ & $\begin{array}{c}\text { Brasil } \\
(2015 b)\end{array}$ & $\begin{array}{l}\text { Ministério da } \\
\text { Agricultura, } \\
\text { Pecuária e } \\
\text { Abastecimento }\end{array}$ & $\begin{array}{l}\text { Estabelece, em todo o território nacional, as normas } \\
\text { específicas de inspeção e a fiscalização sanitária de } \\
\text { produtos de origem animal referente às agroindústrias de } \\
\text { pequeno porte }\end{array}$ \\
\hline $\begin{array}{l}\text { Instrução Normativa } \\
\mathrm{n}^{0} 05 \text {, de fevereiro de } \\
2017 \text { (IN05) }\end{array}$ & $\begin{array}{c}\text { Brasil } \\
(2017 b)\end{array}$ & $\begin{array}{l}\text { Ministério da } \\
\text { Agricultura, } \\
\text { Pecuária e } \\
\text { Abastecimento }\end{array}$ & $\begin{array}{l}\text { Estabelece os requisitos para avaliação de equivalência ao } \\
\text { Sistema Unificado de Atenção à Sanidade Agropecuária } \\
\text { relativos à estrutura física, dependências e equipamentos } \\
\text { de estabelecimento agroindustrial de pequeno porte de } \\
\text { produtos de origem animal }\end{array}$ \\
\hline $\begin{array}{l}\text { Decreto no } 9.013 \text {, de } \\
29 \text { de março de } 2017\end{array}$ & $\begin{array}{c}\text { Brasil } \\
(2017 a)\end{array}$ & $\begin{array}{l}\text { Presidência da } \\
\text { República } \\
\text { Casa Civil }\end{array}$ & $\begin{array}{l}\text { Regulamenta a Lei no } 1.283 \text {, de } 18 \text { de dezembro de } 1950 \text {, e } \\
\text { a Lei no } 7.889 \text {, de } 23 \text { de novembro de 1989, que dispõem } \\
\text { sobre a inspeção industrial e sanitária de produtos de } \\
\text { origem animal, atualizando as normas sobre a inspeção } \\
\text { de produtos de origem animal no Brasil. Trata-se na nova } \\
\text { versão do Regulamento e Inspeção Industrial e Sanitária } \\
\text { de produtos de Origem Animal (RIISPOA) }\end{array}$ \\
\hline
\end{tabular}

Fonte: elaborada pela autora (2018). 
Desde as primeiras iniciativas relacionadas ao estímulo ao processamento de alimentos pela agricultura familiar, diversas críticas, pesquisas e pressões de movimentos sociais influenciaram mudanças significativas no marco regulatório sanitário no Brasil. Nesse sentido, uma primeira referência importante foram, no âmbito do estado de Santa Catarina, algumas ações no sentido de estabelecer regras que facilitassem a implantação e legalização de agroindústrias familiares ${ }^{11}$. Esse foi o caso da criação da Lei Estadual no 10.610, aprovada em 1997, no Estado de Santa Catarina (Santa Catarina, 1998) ${ }^{12}$. Após intenso debate, a lei foi promulgada, abrindo espaço para regras sanitárias específicas e adequadas à elaboração e à comercialização de produtos artesanais de origens animal e vegetal em Santa Catarina. Ainda que, na prática, poucas famílias rurais tenham se beneficiado dessa lei devido a pressões e conflitos em âmbito da inspeção e por pressão de grandes agroindústrias (Prezotto, 1999), o debate gerado em torno da criação desse regulamento tomou amplitude nacional e a discussão passou a compor não apenas a agenda de outros estados ${ }^{13}$, mas também a federal.

Como decorrência das experiências do estado de Santa Catarina em propor regulamentos mais alinhados à realidade do processamento de alimentos no âmbito da agricultura familiar, houve desdobramento de uma série de avanços, entre os quais é possível que a proposta de um sistema de equivalência seja o mais relevante. É o caso do Sistema Brasileiro de Inspeção de Produtos de Origem Animal (SISBI-POA), que faz parte do Sistema Unificado de Atenção à Sanidade Agropecuária (SUASA), constituído por meio da Lei no 9.712, de novembro de 1998 (Brasil, 1998). Esse Sistema, que busca padronizar e harmonizar, em todo o território nacional, procedimentos de inspeção de produtos de origem animal para garantir a inocuidade e a segurança dos alimentos, tornou-se vigente a partir do Decreto no 5.741/2006 (Brasil, 2006), que regulamentou o funcionamento do SUASA.

Grosso modo, a proposta desse sistema é que a inspeção de produtos de origem animal se torne integrada de modo que, em vez de cada serviço de inspeção (municipal, estadual e federal) atuar isoladamente, passem a fazer parte de um único sistema. Dessa forma, não há restrição entre a comercialização intermunicipal, para o caso da inspeção municipal, e a interestadual, para o caso da inspeção estadual, superando a crítica, apontada como uma das maiores incoerências da inspeção de alimentos no Brasil, de que, para o caso de produtos de origem animal, no município em que são processados, não fariam mal aos consumidores, mas, cruzando as fronteiras do município, seriam um risco à saúde da população. Nesse sentido, Prezotto, em palestra proferida em Goiânia, em junho de 2017, argumenta que a questão subjacente não está na esfera da sanidade dos produtos e da segurança dos consumidores, mas sim em questões de garantia de mercado, uma vez que restringido o produto ao local de produção, este terá concorrência restrita.

Somando-se aos esforços e avanços conferidos pela proposta de um sistema unificado de inspeção, outra mudança no conjunto de normas sanitária para o processamento de alimentos é a Instrução Normativa no 16/2015 (IN 16/2015) (Brasil, 2015b), que estabelece, em todo o território nacional, normas específicas de inspeção e a fiscalização sanitária de produtos de origem animal, referentes às agroindústrias de pequeno porte e, ainda mais recente, a Instrução Normativa no 05/2017 (IN 05/2017) (Brasil, 2017b), que estabelece os requisitos para avaliação de equivalência ao Sistema Unificado de Atenção à Sanidade

\footnotetext{
${ }^{11}$ Cabe registrar que, não ao acaso, o estado de Santa Catarina foi o pioneiro em propor um marco legal aderente às características do processamento de alimentos pela agricultura familiar. No estado, convivem, principalmente no oeste catarinense, grandes complexos agroindustriais e empreendimentos da agricultura familiar, seja de forma integrada às agroindústrias para a produção de matérias-primas, principalmente aves e suínos, como mostra o clássico estudo de Paulilo (1990), seja, mais recentemente, protagonizando projetos voltados à agroindustrialização (Mior, 2005). Vale ter presente, por exemplo, que o estado foi um dos primeiros a receber recursos do PronafAgroindústria, contemplando dois projetos, um no Oeste e outro na região sul do estado.

${ }^{12}$ Sobre o contexto em que essa lei foi aprovada, veja Prezotto (1999), que avalia o processo de criação da Lei Estadual no 10.610 e o ambiente institucional no qual as agroindústrias familiares estavam inseridas, especialmente no que concerne às questões sanitárias.

${ }^{13}$ Para um melhor entendimento das discussões que orientaram a construção de argumentos que subsidiaram mudanças no marco sanitário brasileiro para o processamento de alimentos, veja Prezotto (1997).
} 
Agropecuária relativos à estrutura física, a dependências e equipamentos de estabelecimento agroindustrial de pequeno porte para produtos de origem animal.

No que se refere à IN no- 16/2015, que institui medidas que normatizam a agroindustrialização de produtos de origem animal nos estabelecimentos de pequeno porte, é indiscutível os avanços que esta representa para o processamento em agroindústrias familiares. Sem aprofundar os vários aspectos em que essa norma é inovadora, cabe destacar que o art. 3o prevê considerar inclusive as condições estruturais e de controle de processo, respeitando princípios que, entre outros, dizem respeito à inclusão social e produtiva e à harmonização de procedimentos para promover a formalização e a segurança. No art. 5ํㅡ, há menção ao caráter das ações de inspeção e fiscalização, que deverão ter natureza prioritariamente orientadora e linguagem acessível ao empreendedor.

Já a IN no 05/2017 estabelece os requisitos para avaliação de equivalência ao Sistema Unificado de Atenção à Sanidade Agropecuária relativos à estrutura física, a dependências e equipamentos de estabelecimento agroindustrial de pequeno porte de produtos de origem animal. Esse regulamento está estruturado em três capítulos, que se referem ao processamento em estabelecimentos agroindustriais de pequeno porte relativos, respectivamente, a leite e derivados, a produtos das abelhas e derivados e a ovos de galinha e ovos de codorna e derivados. É importante frisar que, apesar de a construção desse regulamento ter passado por consulta pública e ter sido discutido com organizações da agricultura familiar e pesquisadores dedicados ao tema, em grupos de trabalhos mediados pelo então Ministério do Desenvolvimento Agrário, a publicação da norma pouco contemplou dos debates realizados ${ }^{14}$. Como consequência, ao longo de toda essa Instrução Normativa, a IN no 16/2015 não é retomada, seja na forma de escrita, seja em relação ao caráter orientador e inclusivo proposto pela IN no 16/2015, evidenciando retrocesso importante nos avanços realizados na última década em relação ao ambiente institucional e, principalmente, relacionado à fiscalização sanitária de produtos oriundos de agroindústrias familiares.

De fato, o que o SUASA aventou como novas possibilidades para a legalização de agroindústrias familiares no Brasil poderia encontrar na IN no 0 16/2015 grande suporte para sua operacionalização, uma vez que, nesse caso, os serviços de inspeção municipais e estaduais, ao seguir esse regulamento, viabilizariam ações de inclusão produtiva com segurança sanitária. No entanto, a publicação da IN no 05/2017, muito mais alinhada às exigências do RIISPOA que, como já discutido, é o regulamento central da inspeção elaborada com base na realidade da produção em larga escala, representa desafios que já se pensava superados.

Ainda em relação aos produtos de origem animal, vale mencionar a recente publicação da Lei no 13.680, de junho de 2018 (Brasil, 2018). Esse é o primeiro regulamento que, explicitamente, faz menção ao processamento artesanal de alimentos. Essa lei apresenta alguns aspectos inovadores, como é o caso de menção à produção artesanal e a proposta do "Selo Arte" como forma de distinguir alimentos processados de forma artesanal e também ao fato de que, a partir da publicação dessa Lei, esses alimentos poderiam ser comercializados em todo o território nacional, desde que submetidos à fiscalização de órgãos de saúde pública dos estados e do Distrito Federal. Embora inovadora em relação aos aspectos mencionados, essa lei ainda não foi regulamentada ${ }^{15}$, deixando em aberto uma série de dúvidas quanto a sua operacionalização, em especial no que se refere à fiscalização desses produtos e ao enquadramento conceitual do que seriam alimentos

\footnotetext{
${ }^{14}$ Vale ter presente que o processo democrático de debates e construção de normas para o processamento de alimentos pela agricultura familiar vinha sendo estimulado pela Secretaria da Agricultura Familiar, vinculada ao Ministério do Desenvolvimento Agrário. Como decorrência da crise política do Brasil e afastamento da presidente da República em maio de 2016, esse Ministério passou a ser uma Secretaria, a Secretaria Especial de Agricultura Familiar e do Desenvolvimento Agrário, ligada à Casa Civil. Com essa mudança, a forma participativa de discussão nas normas é desconsiderada, mudança que fica explícita na IN no 5/2017.

${ }^{15}$ Após este artigo ser aceito para publicação, foi publicado o Decreto no 9.918, de 18 julho de 2019 (Brasil, 2019), que regulamenta a Lei SELO ARTE. Para mais informações sobre esse regulamento, veja a publicação Produtos agroalimentares artesanais brasileiros: situação atual e potencial de valorização (Domit \& Cruz, 2019).
} 
artesanais. Dessa forma, ainda que esse regulamento traga elementos inovadores, as divergências em torno de sua aplicabilidade, decorrentes em boa medida do modo não participativo com que a lei foi construída e publicada, não permitem afirmar, antes da publicação do decreto que a regulamente, se ela implicará, de fato, avanços no que se refere ao reconhecimento e à possibilidades de legalização da produção artesanal e tradicional de alimentos pela agricultura familiar.

Em relação aos alimentos de origem vegetal, é central a referência à Resolução RDC no 49, publicada em 31 de outubro de 2013. Essa Resolução apresenta entre suas diretrizes a "proteção à produção artesanal a fim de preservar costumes, hábitos e conhecimentos tradicionais na perspectiva do multiculturalismo dos povos, comunidades tradicionais e agricultores familiares" e o "fomento de políticas públicas e programas de capacitação para - microempreendedor individual, empreendimento familiar rural e empreendimento econômico solidário, como forma de eliminar, diminuir ou prevenir riscos à saúde e promover a segurança sanitária" (Brasil, 2013, Cap. I, art. 5). Além disso, esse regulamento evidencia a relevância da legalização da produção de alimentos em pequena escala, tendo em vista a inclusão produtiva com garantia da segurança dos alimentos, preservando e valorizando hábitos alimentares tradicionais.

Cada um dos regulamentos mencionados nesta seção pode ser analisado com mais profundidade, mas o que interessa aqui é analisar, de forma mais ampla, os avanços realizados no marco sanitário no que se refere às possibilidades colocadas para a legalização do processamento de alimentos em agroindústrias familiares. Na última década, sem dúvida, foi possível construir um cenário que, do ponto de vista de exigências sanitárias, possibilita revogar argumentos cabíveis há dez anos que, como já apresentados, permitiam afirmar que o marco regulatório para a legalização de agroindústrias familiares era inadequado e excludente.

Porém, em que pesem os avanços principalmente da última década no que diz respeito a regulamentos sanitários mais alinhados às características e à escala de produção da agricultura familiar, retomando a discussão central deste artigo, é preciso considerar que tais avanços requerem, de todo modo, o deslocamento da produção em escala doméstica para a escala industrial, ainda que em pequena escala. Para tanto, é necessário considerar questões como organização produtiva para viabilizar escala de produção de matériasprimas ou logística para aquisição de parte das matérias-primas em outras propriedades, organização do trabalho feminino e mudança de um modelo de processamento pautado na diversificação para um que, para justificar e viabilizar investimentos financeiros, focará em poucos produtos. Aqui novamente cabe repensar o termo "indústria", pois, no limite, agroindústrias familiares, como o nome sugere, são indústrias.

Para as famílias que dispõem de escala de produção e/ou organização familiar que viabilize investimentos para a legalização, apesar dos retrocessos que a IN no 05/2017 representa, comparativamente ao contexto dos anos 2000 , em que o único regulamento a ser seguido para o processamento de alimentos era o RIISPOA, a situação atual não é de todo negativa. Contudo, considerando a realidade e características do processamento de alimentos no âmbito da agricultura familiar e a ampla informalidade presente no setor, a questão que fica para análise diz respeito não apenas aos passos necessários para que as normas vigentes proporcionem a legalização de número maior de agroindústrias, mas também (e principalmente) ao enfoque mais adequado para que o contingente de famílias que processam em âmbito doméstico seja também contemplado, desafio que parece estar ainda mais distante de ser resolvido.

Conforme argumenta Deon (2015, p. 36), a “[...] informalidade é potencializada pela necessidade de expandir a produção e comercialização [...], o que passa a ser necessário decorrente do aumento de escala estimulado pelo processo de formalização". O autor avalia que, além desse aumento de escala, a pressão exercida pelo ambiente institucional está associada também ao cumprimento de exigências relacionadas aos aspectos sanitário, tributário, previdenciário e ambiental, as quais se somam às justificativas para a informalidade, principalmente em mercados locais. $O$ autor destaca também a influência de aspectos culturais e limitações como logística e mão de obra disponível, por exemplo, para a manutenção da situação de informalidade. 
Segundo Deon (2015, p. 36),

trata-se de reconhecer a existência de agroindústrias que estão na informalidade por opção dos próprios agricultores, mas também daquelas iniciativas que estão na informalidade por uma questão de restrições, dificuldades para avançar no processo de formalização.

Alinhado a mesma perspectiva, Bigheline da Silveira (2013) explica que muitas famílias produtoras são favoráveis ao comércio informal, argumentando a importância econômica que, embora não se expresse por meio de uma renda elevada oriunda da comercialização desses produtos, se justifica pelo fato de que, por estarem associados ao autoconsumo, os produtos, além de serem comercializados, também estão disponíveis para consumo da família. Além disso, o autor argumenta que, para além da questão econômica, por meio da comercialização desses produtos, a identidade de produtor(a) familiar é mantida.

De todo modo, apesar da perspectiva apresentada até aqui que, em alguma medida, justifica ações e decisões de famílias agricultoras que processam e comercializam alimentos à margem do setor formal, o argumento que se pauta na garantia da saúde pública, recorrente nos discursos dos diversos atores que possuem mais voz nesse debate, como é o caso de profissionais responsáveis pela inspeção e fiscalização da produção e processamento de alimentos, é indiscutível. Portanto, se garantia da saúde pública é o argumento central para orientar o processamento de alimentos, é preciso colocar na agenda a realidade dessa produção que, ainda que informal, como já discutimos, encontra caminhos e meios para estar no mercado. Não se trata, portanto, de negligenciar esse modo de processamento ou condená-lo a priori, mas sim, seguindo alguns princípios que orientam os regulamentos sanitários mais recentes, se debruçar com mais profundidade para avaliar meios sobre como contribuir para que a singularidade desses produtos seja preservada e, ao mesmo tempo, independentemente da escala de produção, seja possível contemplar critérios que viabilizem sua qualificação e legalização.

Do ponto de vista da fiscalização, os desafios dizem respeito particularmente à operacionalização desses novos regulamentos. Nesse sentido, uma década é realmente pouco tempo para que fiscais responsáveis pela fiscalização e inspeção de alimentos possam ajustar suas condutas de modo que estejam alinhadas com noções como fiscalização orientadora e inclusão produtiva. No limite, como explicam alguns fiscais, o estado não dá amparo jurídico a eles, de modo que ações fiscalizatórias passíveis de serem interpretadas como permissivas podem resultar em processos pessoais que, inclusive, podem comprometer a carreira desses profissionais. Nessa análise, não estamos, evidentemente, considerando situações como as deflagradas na Operação Carne Fraca ${ }^{16}$, mas sim considerando que os profissionais responsáveis para inspeção e fiscalização agem corretamente, de acordo com o código de ética de sua profissão.

\section{Considerações finais}

Muito mais do que encerrar o debate e esgotar a análise sobre conceitos, definições e regulamentos que incidem sobre o processamento de alimentos em pequena escala, este artigo buscou uma ampla aproximação ao tema, deixando em aberto, certamente, outras questões e leituras mais minuciosas que abordem e aprofundem as diversas nuances que constituem a temática. De todo modo, vale destacar que a sistematização que contribui para conceituar a produção tradicional e artesanal de alimentos e a distinguir do processamento de alimentos em agroindústrias de pequeno porte pela agricultura familiar é ponto de partida para esta e, porventura, outras análises que merecem ser feitas sobre o

\footnotetext{
${ }^{16}$ A Operação Carne Fraca, deflagrada em março de 2017, trouxe à tona amplo esquema de corrupção entre fiscais e frigoríficos em vários estados do Brasil, com o intuito de burlar controles sanitários. O caso, explorado de forma midiática e, em boa medida especulativo, acompanhou todos os passos da investigação da Polícia Federal, sem análise ou mediação que possibilitasse às autoridades serem capazes de efetivamente dimensionar a amplitude das irregularidades. Para mais informações, veja Agência Brasil (2018).
} 
tema. De fato, como se procurou demonstrar, para além das agroindústrias familiares rurais, amplamente estimuladas como forma de fortalecer estratégias de agregação de valor aos produtos e de renda às famílias rurais, o processamento de alimentos pela agricultura familiar e, marcadamente, pelas mulheres rurais é histórico e continua sendo realizado por muitas famílias. Porém, se o reconhecimento do processamento de alimentos pela agricultura familiar encontra espaço no que diz respeito às agroindústrias, no que se refere ao processamento feito no espaço doméstico há poucos estudos que possam aportar informações qualitativas e quantitativas que permitam compreender a amplitude e características dessa atividade.

No contexto dessa produção, embora a quantidade de produtos resultante do processamento de alimentos em cada família seja pequena e orientada ao autoconsumo, é importante ter presente que, no caso da totalidade das famílias que desenvolve esse tipo de atividade, pode-se argumentar, como se buscou evidenciar neste trabalho, que essa é uma produção expressiva. Entretanto, na medida em que não é reconhecida, não há nenhuma política de apoio que as contemple. Desse modo, o processamento tradicional de alimentos se mantém na informalidade e, estando invisibilizado, pouco será possível avançar em relação à qualificação e/ou à legitimação da qualidade desses produtos.

Nesse sentido, o argumento de que a informalidade não é a via para a qualidade pode ser acionado. De fato, é preciso reconhecer e encontrar meios para que, independentemente da escala, o processamento de alimentos seja reconhecido e possa ter meios para se qualificar. Do contrário, mantendo formas tradicionais de processamento negligenciadas, o risco à saúde pública, argumento principal das críticas à informalidade, torna-se válido.

Ainda que, de modo geral, muitos avanços tenham ocorrido nos últimos dez anos, como os regulamentos abordados neste artigo evidenciam, nos últimos anos tais avanços têm sido marcados por retrocessos decorrentes ou agravados pela situação política atual do país. Nesse quadro, ainda que regulamentos como a RDC № 49/2013, a IN no 16/2015 e a Lei no 13.680/2018 aportem potencialidades não apenas para a legalização de agroindústrias familiares, mas também para o processamento tradicional e artesanal de alimentos, a situação atual, com a publicação de regulamentos como a IN № 05/2017, por exemplo, indica retrocessos, inviabilizando, em boa medida, o incipiente diálogo que estava em construção com a (e na) sociedade não apenas para reconhecer a heterogeneidade do processamento de alimentos, mas também para legitimar a diversidade das formas de produção e de processamento de alimentos no Brasil.

\section{Referências}

Agência Brasil. (2018). Sete perguntas e respostas sobre a Operação Carne Fraca. Brasília: Agência Brasil. Recuperado em 15 de junho de 2018, de http://agenciabrasil.ebc.com.br/geral/noticia/201703/sete-perguntas-e-respostas-sobre-operacao-carne-fraca

Agne, C. L., \& Waquil, P. D. (2011). Redes de proximidade: agricultores, instituições e consumidores na construção social de mercados para os produtos das agroindústrias rurais familiares na região central do RS. Redes (Santa Cruz do Sul. Online), 16, 164-186.

Bigheline da Silveira, L. (2013). Agricultura familiar e informalidade: o seu papel no abastecimento local de alimentos (Tese de doutorado). Programa de Pós-graduação em Extensão Rural, Universidade Federal de Santa Maria, Santa Maria.

Brasil. Presidência da República. Casa Civil. (1950). Lei n 1.283, de 18 dezembro de 1950. Dispõe sobre a inspeção industrial e sanitária dos produtos de origem animal. Diário Oficial [da] República Federativa do Brasil, Brasília. Recuperado em 27 de julho de 2011, de http://www.planalto.gov.br/ccivil_03/Leis/L1283.htm

Brasil. Presidência da República. Casa Civil. (1952). Decreto n 30.691, de 29 de março de 1952. Regulamenta a Lei $n^{\circ} 1.283$, de 18 de dezembro de 1950, e a Lei $n^{\circ} 7.889$, de 23 de novembro de 1989, que dispõem sobre a inspeção industrial e sanitária de produtos de origem animal. Diário Oficial [da] República Federativa do Brasil, Brasília. Recuperado em 27 de julho de 2011, de http://www.planalto.gov.br/ccivil_03/decreto/1950 1969/D30691.htm

Brasil. Presidência da República. Secretaria-Geral. Subchefia para Assuntos Jurídicos. (1998). Lei nº 9.712, de 20 de novembro de 1998. Altera a Lei no 8.171, de 17 de janeiro de 1991, acrescentando- 
Ihe dispositivos referentes à defesa agropecuária. Diário Oficial [da] República Federativa do Brasil, Brasília. Seção 1, p. 9. Recuperado em 23 de novembro de 1998,

https://www2.camara.leg.br/legin/fed/lei/1998/lei-9712-20-novembro-1998-352652-norma-pl.html.

Brasil. Presidência da República. Casa Civil. (1989). Lei n 7.889, de 23 de novembro de 1989. Dispõe sobre inspeção sanitária e industrial dos produtos de origem animal. Diário Oficial [da] República Federativa do Brasil, Brasília. Recuperado em 15 de dezembro de 2017, de http://www.planalto.gov.br/ccivil_03/leis/L7889.htm

Brasil. Presidência da República. Casa Civil. (2006). Decreto n 5.741, de março de 2006. Regulamenta os arts. 27-A, 28-A e 29-A da Lei n 8.171, de 17 de janeiro de 1991, organiza o Sistema Unificado de Atenção à Sanidade Agropecuária. Diário Oficial [da] República Federativa do Brasil, Brasília. Recuperado em 15 de novembro de 2017, de http://www.planalto.gov.br/ccivil_03/_ato20042006/2006/decreto/d5741.htm

Brasil. Ministério da Saúde. (2013, novembro 1). Resolução RDC n 49, de 31 de outubro de 2013. Diário Oficial [da] República Federativa do Brasil, Brasília. Seção 1, p. 56. Recuperado em 3 de novembro de 2013, de http://pesquisa.in.gov.br/imprensa/jsp/visualiza/index.jsp?jornal=1\&pagina=56\&data=01/11/2013

Brasil. Presidência da República. Secretaria-Geral. Subchefia para Assuntos Jurídicos. (2015a). Decreto $n^{\circ} 8.471$, de 22 de junho de 2015. Altera o Anexo ao Decreto $n^{\circ} 5.741$, de 30 de março de 2006, que regulamenta os arts. 27-A, 28-A e 29-A da Lei n 8.171, de 17 de janeiro de 1991, e organiza o Sistema Unificado de Atenção à Sanidade Agropecuária. Diário Oficial [da] República Federativa do Brasil, Brasília. Seção 1, p. 9. Recuperado em 23 de junho de 2013, de http://pesquisa.in.gov.br/imprensa/jsp/visualiza/index.jsp?data=23/06/2015\&jornal=1 \&pagina=9\&t otalArquivos $=168$

Brasil. Ministério da Agricultura, Pecuária e Abastecimento. (2015b). Instrução Normativa n 16, de 23 de junho de 2015. Estabelece as normas específicas de inspeção e a fiscalização sanitária de produtos de origem animal, referente às agroindústrias de pequeno porte. Diário Oficial [da] República Federativa do Brasil, Brasília. Recuperado em 18 de junho de 2017, de https://www.legisweb.com.br/legislacao/?id=286090

Brasil. Presidência da República. Casa Civil. (2017a). Decreto n 9.013, de 29 de março de 2017. Novo Regulamento de Inspeção Industrial e Sanitária de Produtos de Origem Animal (RIISPOA). Diário Oficial [da] República Federativa do Brasil, Brasília. Recuperado em 24 de janeiro de 2018, de http://www.planalto.gov.br/ccivil_03/_ato2015-2018/2017/decreto/D9013.htm

Brasil. Ministério da Agricultura, Pecuária e Abastecimento. (2017b). Instrução Normativa $n^{\circ}$ 5, de 14 de fevereiro de 2017. Estabelece os requisitos para avaliação de equivalência ao Sistema Unificado de Atenção à Sanidade Agropecuária relativos à estrutura física, dependências e equipamentos de estabelecimento agroindustrial de pequeno porte de produtos de origem animal. Diário Oficial [da] República Federativa do Brasil, Brasília. Recuperado em 15 de julho de 2017, de http://www.agricultura.gov.br/assuntos/inspecao/produtos-animal/sisbi1/legislacao/InstruoNormativa_05.2017.pdf

Brasil. Presidência da República. Casa Civil. (2018). Lei n¹3.680, de 14 de junho de 2018. Altera a Lei $n^{\circ}$ 1.283 , de 18 de dezembro de 1950, para dispor sobre o processo de fiscalização de produtos alimentícios de origem animal produzidos de forma artesanal. Diário Oficial [da] República Federativa do Brasil, Brasília. Recuperado em 17 de junho de 2018, de http://www.planalto.gov.br/ccivil_03/_ato2015-2018/2018/Lei/L13680.htm

Brasil. Presidência da República. Casa Civil. (2019). Decreto n 9.918, de 18 julho de 2019. Regulamenta o art. 10-A da Lei n 1.283 , de 18 de dezembro de 1950, que dispõe sobre o processo de fiscalização de produtos alimentícios de origem animal produzidos de forma artesanal. Diário Oficial [da] República Federativa do Brasil, Brasília. Recuperado em 19 de julho de 2019, de http://www.in.gov.br/web/dou/-/decreto-n-9918-de-18-de-julho-de-2019-198615217

Chalita, M. A. N., Pithan e Silva, R. O., Petti, R. H. V., \& Silva, C. R. L. (2009). Algumas considerações sobre a fragilidade das concepções de qualidade no Mercado de queijos no Brasil. Informações Econômicas, 39(6), 77-88.

Craviotti, C., \& Palacios, P. (2014). La diversificación de los mercados como estrategia de la agricultura familiar. Revista de Economia e Sociologia Rural - RESR, 51(supl. 1), S063-S078.

Cristóvão, A. (2002). Mundo rural: entre as representações (dos urbanos) e os benefícios reais (para os rurais). In M. Riedl, J. A. Almeida, \& A. L. B. V. Barbosa (Orgs.), Turismo rural: tendências e sustentabilidade (p. 81-116). Santa Cruz do Sul: Editora Unisc. 
Cruz, T. F. (2007). Qualidade e boas práticas de fabricação em um contexto de agroindústrias rurais de pequeno porte (Dissertação de mestrado). Programa de Pós-graduação em Agroecossistemas, Centro de Ciências Agrárias, Universidade Federal de Santa Catarina, Santa Maria.

Cruz, T. F. (2012). Produtores, consumidores e valorização de produtos tradicionais: um estudo sobre qualidade de alimentos a partir do caso do queijo Serrano dos Campos de Cima da Serra - RS (Tese de doutorado). Programa de Pós-Graduação em Desenvolvimento Rural, Universidade Federal do Rio Grande do Sul, Porto Alegre.

Cruz, T. F., \& Schneider, S. (2010). Qualidade dos alimentos, escalas de produção e valorização de produtos tradicionais. Revista Brasileira de Agroecologia, 5(2), 1-18.

Delfosse, C. (1995). La notion de tradition en question: le fromage entre tradition et modernité en France. In N. Eizner (Org.). Voyage en alimentation (pp. 251-261). Paris: ARF.

Deon, P. R. C. (2015). A contribuição dos atores na trajetória de formalização das agroindústrias familiares rurais em Jaguari-RS e Chapecó-SC (Tese de doutorado). Programa de Pós-graduação em Extensão Rural, Universidade Federal de Santa Maria, Santa Maria.

Domit, A. L., \& Cruz, F. T. (2019). Produtos agroalimentares artesanais brasileiros: situação atual e potencial de valorização. Recuperado em 15 de junho de 2019, de https://www.embrapa.br/documents/44800246/47366122/Produtos+agroalimentares+situa\%C3\%A 7\%C3\%A3o+atual/55bf9d89-96f2-b443-4822-5a888be3ffb1.

Dorigon, C. (2008). Mercados de produtos coloniais da região Oeste de Santa Catarina: em construção (Tese de doutorado). Programa de Engenharia de Produção, Coordenação dos Programas de PósGraduação de Engenharia Universidade Federal do Rio de Janeiro, Rio de Janeiro.

Eizner, N. (1995). Préface. In E. Nicole (Org.). Voyage en alimentation (pp. 11-16). Paris: ARF.

Fernandes Filho, J. F., \& Campos, F. R. (2003). A indústria rural no Brasil. Revista de Economia e Sociologia Rural, 41(4), 859-880.

Fonte, M. (2010). Food relocalisation and knowledge: dynamics for sustainability in rural areas. In M. Fonte, \& A. G. Papadopoulos (Eds.), Naming food after places: food relocalisation and knowledge dynamics in rural development (pp. 1-35). Farnham: Ashgate.

Fonte, M. (2008). Knowledge, food and place: a way of producing, a way of knowing. Sociologia Ruralis, $48(3), 200-222$.

Garcia, R. W. D. (2003). Reflexos da globalização na cultura alimentar: considerações sobre as mudanças na alimentação urbana. Revista de Nutrição, 16(4), 483-492.

Gazolla, M. (2013). Redefinindo as agroindústrias no Brasil: uma conceituação baseada em suas condições alargadas de reprodução social. Revista IDEAS (Online), 7, 62-95.

Giddens, A. (1997). A vida em uma sociedade pós-tradicional. In U. Beck, A. Giddens, \& S. Lash (Orgs.), Modernização reflexiva: política, tradição e estética na ordem social moderna (pp. 73-133). São Paulo: UNESP.

Graziano da Silva, J. (1996). A nova dinâmica da agricultura brasileira. Campinas: UNICAMP.

Grisa, C. (2007). Para além da alimentação: papéis e significados da produção para autoconsumo na agricultura familiar. Extensão Rural, 14, 5-35.

Instituto Brasileiro de Geografia e Estatística - IBGE. Sistema IBGE de Recuperação Automática - SIDRA. (2006). Censo agropecuário de 2006. Rio de Janeiro: IBGE. Recuperado em 27 de dezembro de 2017, de http://www.ibge.gov.br

Kneafsey, M. et al. (2008). Reconnecting consumers, producers and food: exploring alternatives. New York: Berg.

Lee, J., Gereffi, G., \& Beauvais, J. (2012). Global value chains and agrifood standards: challenges and possibilities for smallholders in developing countries. Proceedings of the National Academy of Sciences of the United States of America, 109(31), 12326-12331.

Maloney, W. F. (2003). Informal self-employment: poverty trap or decent alternative? In G. Fields, \& G. Pfeffermann (Eds.), Pathways out of poverty (pp. 65-82). Dordrecht: Kluwer.

Menasche, R. (2003). Os grãos da discórdia e o risco à mesa: um estudo antropológico das representações sociais sobre cultivos e alimentos transgênicos no Rio Grande do Sul (Tese de Doutorado). Programa de Pós-Graduação em Antropologia Social, Instituto de Filosofia e Ciências Humanas, Universidade Federal do Rio Grande do Sul, Porto Alegre.

Menasche, R. (2010). Campo e cidade, comida e imaginário: percepções do rural à mesa. Ruris, 3(2), 195-218. 
Mior, L. C. (2005). Agricultores familiares, agroindústrias e redes de desenvolvimento rural. Chapecó: Argos.

Murdoch, J., \& Miele, M. (1999). "Back to nature": changing "worlds of production" in the food sector. Sociologia Ruralis, 39(4), 465-483.

Murdoch, J., \& Miele, M. (2004). A new aesthetic of food? Relational reflexivity in the 'alternative' food movement. In M. Harvey, A. McMeekin, \& A. Warde (Eds.), Qualities of food (pp. 156-175). New York: Palgrave.

Paulilo, M. I. S. (1990). Produtor e agroindústria: consensos e dissensos. Florianópolis: UFSC.

Pellegrini, G., \& Gazolla, M. (2008). A agroindústria familiar no Rio Grande do Sul: limites e potencialidades a sua reprodução social (200 p.). Frederico Westphalen: URI.

Ploeg, J. D. van der. (2008). Camponeses e impérios alimentares: lutas por autonomia e sustentabilidade na era da globalização. Porto Alegre: Ed. UFRGS.

Prezotto, L. L. (1999). Agroindústria rural de pequeno porte e o seu ambiente institucional relativo à legislação sanitária (Dissertação de mestrado). Programa de Pós-graduação em Agroecossistemas, Centro de Ciências Agrárias, Universidade Federal de Santa Catarina, Florianópolis.

Prezotto, L. L. (1997). A agroindustrialização de pequeno porte: higiene, qualidade e aspectos legais. Revista Agropecuaria Catarinense, 10(4), 8-13.

Prezotto, L. L. (2005). Sustentabilidade da agricultura familiar: implicações da legislação sanitária. Fortaleza: Fundação Konrad Adenauer, Instituto de Assessoria para o Desenvolvimento Humano.

Santa Catarina. Secretaria de Estado do Desenvolvimento Rural e da Agricultura. (1998). Normas sanitárias para a elaboração e comercialização de produtos artesanais comestíveis de origem animal e vegetal. Florianópolis: Secretaria de Estado do Desenvolvimento Rural e da Agricultura.

Sgarbi dos Santos, J. (2006). Agroindústria familiar rural no Alto Uruguai do Rio Grande do Sul: uma análise do processo de comercialização (Dissertação de mestrado). Programa de Pós-graduação em Agroecossistemas, Universidade Federal de Santa Catarina, Florianópolis.

Silveira, P. R. C., \& Heinz, C. U. (2005). Controle de qualidade normativo e qualidade ampla: princípios para re-estruturação e qualificação da produção artesanal de alimentos. In Anais do $1^{\circ}$ Congresso Internacional de Desenvolvimento Rural e Agroindústria Familiar. São Luis Gonzaga: UERGS.

Tregear, A. (2011). Progressing knowledge in alternative and local food networks: critical reflections and a research agenda. Journal of Rural Studies, 27(4), 419-430.

Triches, R. M. (2010). Reconectando a produção ao consumo: a aquisição de gêneros alimentícios da agricultura familiar para o Programa de Alimentação Escolar (Tese de doutorado). Programa de Pósgraduação em Desenvolvimento Rural, Universidade Federal do Rio Grande do Sul, Porto Alegre.

Varga, M. (2017). Cash rather than contract: the re-emergence of traditional agrifood chains in postcommunist Europe. Journal of Rural Studies, 53(1), 58-67.

Wesz Junior, V. J. (2010). Políticas públicas de agroindustrialização na agricultura familiar: uma análise do pronaf-agroindústria. Revista de Economia e Sociologia Rural, 48, 567-596.

Wilkinson, J., Cerdan, C., \& Dorigon, C. (2017). Geographical Indications and origin products in Brazil: the interplay of institutions and networks. World Development, 98, 82-92.

Wilkinson, J., \& Mior, L. C. (1999). Setor informal, produção familiar e pequena agroindústria: interfaces. Estudos Sociedade e Agricultura, (13), 29-45.

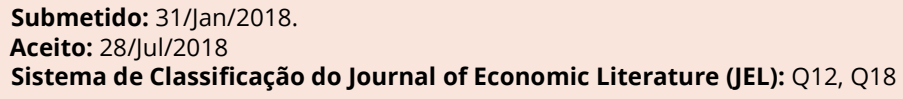

